\title{
SUBSTRATOS E ADUBAÇÃO NITROGENADA NA PRODUÇÃO DE MUDAS DE MARACUJAZEIRO AMARELO
}

\section{SUBSTRATES AND NITROGEN FERTILIZATION IN THE PRODUCTION OF YELLOW PASSION FRUIT TREE SEEDLINGS}

\author{
Csaignon Mariano CAPRONI ${ }^{1}$ \\ Darlan José RAMOS ${ }^{2}$ \\ João VIEIRA NETO ${ }^{3}$ \\ Luiz Fernando de oliveira da SILVA ${ }^{4}$ \\ Juliana Carvalho SIMÕES ${ }^{5}$ \\ Wilson Roberto PEREIRA ${ }^{6}$
}

\section{RESUMO}

A produção de mudas de maracujazeiro amarelo de boa qualidade genética e fitossanitária, bem nutridas e precoces é de suma importância, tanto para pegamento como para sobrevivência no campo. A multiplicação rápida depende de alguns fatores preponderantes, ligados especificamente aos substratos e complementações com adubações. Para tentar minimizar esses problemas e oferecer alternativas na propagação por sementes do maracujazeiro amarelo foi proposto o presente experimento visando à produção de mudas em dois diferentes substratos com adubações nitrogenadas, na forma de uréia, em cobertura. $O$ trabalho foi conduzido no telado do viveiro de formação de mudas da Universidade Federal de Lavras, MG. Foram testadas cinco doses de nitrogênio $\left(0 ; 400 ; 800 ; 1600\right.$ e $3200 \mathrm{mg} \mathrm{N} \mathrm{dm}^{-3}$ de substrato) e duas composições de substratos: A (Provaso ${ }^{\circledR}+$ areia + terra de subsolo, na proporção de 1:1:3 em volume) e B (Plantmax ${ }^{\circledR}+$ areia + terra de subsolo, na proporção de 1:1:3 em volume ). O delineamento experimental utilizado foi em blocos ao acaso, em esquema fatorial $5 \times 2$, com 4 repetições e cinco plantas por parcela. Decorridos 120 dias após a semeadura foram avaliados o comprimento da parte aérea $(\mathrm{cm})$; número de folhas por planta, massa seca da parte aérea, da raiz e total $(\mathrm{g}$ planta ${ }^{-1}$ ). A utilização de adubações nitrogenadas em cobertura em doses de até $2000 \mathrm{mg} \mathrm{N} \mathrm{dm}^{-3}$ de substrato permitiram a formação de mudas de maracujazeiro amarelo de melhor qualidade. As misturas A (Provaso ${ }^{\circledR}+$ areia + terra de subsolo) e $B$ $\left(\right.$ Plantmax $^{\circledR}+$ areia + solo) proporcionaram resultados semelhantes, entretanto a mistura $B$ se destacou para algumas características avaliadas, proporcionando melhor desenvolvimento às mudas do maracujazeiro amarelo.

Palavras-chave: Passiflora edulis f. flavicarpa; adubação orgânica e nitrogenada; propagação.

\section{ABSTRACT}

The production of yellow passion fruit tree seedlings of high genetic, phytosanitary quality, well nourished and early is very important, both for taking on and for survival in the field. The fast multiplication depends on a few preponderant factors linked specifically to substrates and complementation with fertilizations. To minimize these problems and offer alternatives in the seed propagation of the yellow passion fruit tree, the present experiment was proposed aiming at seedling production in two different substrates with nitrogen topdressing in the form of urea. This work was conducted in the screening of the seedling nursey of the Universidade Federal de Lavras, MG. Five doses of nitrogen $\left(0 ; 400 ; 1600\right.$; and $3200 \mathrm{mg} \mathrm{N} \mathrm{dm}^{3}$ of substrate) and two compositions of substrates: A (Provaso ${ }^{\circledR}+$ sand + subsoil at the ration of $1: 1: 3$ in volume) and $B$ (Plantmax ${ }^{\circledR}+$ sand + subsoil at the ratio of 1:1:3 in volume) were tested. The experimental design utilized was a randomized block with four replicates com treatments disposed in $5 \times 2$ factorial scheme, and five plants per plot. Past 120 days after sowing, the following characteristics were evaluated: length of the shoot $(\mathrm{cm})$; number of leaves/plant, dry matter of the shoot, of the root and total $\left(\mathrm{g} \mathrm{plant}^{-1}\right.$ ). The use of nitrogen fertilization in coverage at rates of up to $2000 \mathrm{mg} \mathrm{N} \mathrm{dm}^{-3}$ substrate allowed the formation of yellow passion fruit of better quality. The mixtures, A (Provaso ${ }^{\circledR}+$ sand + subsoil) and B (Plantmax ${ }^{\circledR}+$ sand $+^{\circ}$ subsoil) provided similar results however the mixture B stood out for some traits evaluated, providing the best development for yellow passion fruit seedlings.

Key-words: Passiflora edulis f. flavicarpa; organic fertilization; nitrogen fertilization; propagation.

\footnotetext{
${ }^{1}$ Eng. Agr. M. Sc. Bolsista FAPEMIG. Empresa de Pesquisa Agropecuária de Minas Gerais. Av. Prefeito Tuany Toledo, 470 Sala 8. UNIVAS. 37550-000. Pouso Alegre - MG. E-mail: caproni@epamig.br

${ }^{2}$ Eng. Agr. D. Sc. Professor do Depto. de Agricultura - Universidade Federal de Lavras. Campus Universitário, 3037, 37200000. Lavras - MG. E-mail: darlan@ufla.br

${ }^{3}$ Eng. Agr. D. Sc. Empresa de Pesquisa Agropecuária e Extensão de Santa Catarina, Cx postal 121, 88400-000. Ituporanga SC.E-mail: joaoneto@epagri.sc.gov.br

${ }^{4}$ Eng. Agr. M. Sc. Bolsista CAPES. Empresa de Pesquisa Agropecuária de Minas Gerais. Rua Washington Alvarenga Viglione, s/n, 37517-000. Maria da Fé - MG. E-mail: luizfernando.agronomia@gmail.com

${ }^{5}$ Eng. Agr. M. Sc. Empresa de Pesquisa Agropecuária de Minas Gerais. Av. José Candido da Silveira, 1647, 31170-000. Belo Horizonte - MG. E-mail: jcsimoes@epamig.br

${ }^{6}$ Eng. Agr. D. Sc. Instituto Federal de Educação, Ciência e Tecnologia Sul de Minas Gerais - Campus Inconfidente, Praça Tiradentes, 416, 37576-000. Inconfidentes - MG. E-mail: wrpufla@yahoo.com.br
} 
CARPONI C. M., et al. Substratos e adubação nitrogenada...

\section{INTRODUÇÃO}

O maracujazeiro é uma frutífera trepadeira da família Passifloraceae, com uma larga distribuição, notadamente, nos trópicos. São conhecidas mais de 580 espécies, sendo a maioria nativa da América Tropical, com muitas variedades tendo o Brasil como centro de origem e destacandose como maior produtor de maracujazeiro amarelo (Freitas et al., 2009).

É uma cultura que emprega grande quantidade de mão-de-obra, caracterizando-a como uma atividade agrícola familiar. Em decorrência disso, sua expansão nem sempre é planejada, acarretando grandes perdas de matéria prima produzida, além da utilização de material genético (mudas) de baixa qualidade.

O maracujá amarelo apresenta uma série de características superiores ao maracujá roxo, tais como: maior tamanho do fruto e maior peso. Os híbridos apresentam maior rendimento e produtividade por hectare. No Brasil, o maior produtor é o estado da Bahia (Agrianual, 2008).

A produtividade do maracujazeiro amarelo no Brasil é muito baixa, cerca de $13.395 \mathrm{~kg} \mathrm{ha}^{-1}$ (Carvalho et al., 2010)., devido principalmente, a não utilização de tecnologias adequadas disponíveis, recomendadas para o seu cultivo.

Segundo Rizzi et al. (1998), a implantação de um pomar de maracujazeiro requer um planejamento cuidadoso, pois existe uma sequência lógica nas operações, o que faz com que a não realização de uma prática no momento oportuno, comprometa os resultados finais.

A formação da muda no menor tempo e com o máximo vigor depende das características do substrato utilizado e do manejo em viveiro. A definição desses fatores é preponderante no processo de produção de mudas de qualquer espécie vegetal (Fachinello et al., 2005).

Para a obtenção de mudas de boa qualidade, faz-se necessária a utilização de substratos, os quais devem apresentar, entre outras características, $\mathrm{pH}$ e composição química adequados e fornecer os nutrientes necessários para o desenvolvimento da planta (Soares et al.,2007). Deve-se levar em consideração também o tamanho da semente, sua exigência com relação à umidade, sensibilidade ou não à luz e ainda, a facilidade que este oferece para o desenvolvimento e avaliação de plântulas (Fanti \& Perez, 1999; Ramos et al., 2002).

Diante do exposto o trabalho teve como objetivo testar a combinação de dois substratos com doses crescentes de nitrogênio, visando acelerar o processo de produção de mudas de boa qualidade, bem nutridas, com maior resistência e adaptação no campo.

\section{MATERIAL E MÉTODOS}

O experimento foi conduzido em 2004, no setor de Fruticultura da Universidade Federal de Lavras (UFLA), Lavras - MG, sobre bancadas de madeira suspensas a $1,0 \mathrm{~m}$ do solo sob telado de nylon tipo sombrite, permitindo $50 \%$ de luminosidade no seu interior e uma boa ventilação.

As sementes foram provenientes de plantas matrizes pertencentes ao pomar do setor de Fruticultura da UFLA. Foram semeadas três sementes por saco de polietileno preto com capacidade de $500 \mathrm{~cm}^{3}$, com dimensões de $20 \mathrm{~cm}$ de altura e $10 \mathrm{~cm}$ de diâmetro. Os substratos utilizados na execução deste trabalho foram devidamente desinfestados com solução de hidróxido de sódio e posteriormente lavados em água corrente, sendo estes: A (Provaso ${ }^{\circledR}+$ areia + terra de subsolo na proporção de 1:1:3 em volume) e B (Plantmax ${ }^{\circledR}$ + areia + terra de subsolo na proporção de 1:1:3 em volume). Os resultados da análise química dos diferentes substratos estão descritos nas Tabelas 1 e os nutrientes contidos nos substratos, $\mathrm{Zn}, \mathrm{Fe}, \mathrm{Mn}, \mathrm{Cu}, \mathrm{B}$ e S estão apresentados na Tabela 2

Foram testadas cinco doses de nitrogênio (0; 400; 800; 1600 e $3200 \mathrm{mg} \mathrm{N} \mathrm{dm}^{-3}$ de substrato) aplicadas em cobertura na forma de uréia $(45 \%$ de $\mathrm{N})$. As aplicações foram realizadas a cada 10 dias, sendo que em cada aplicação foram adicionados aos sacos de polietileno $20 \mathrm{~mL}$ da solução contendo $\mathrm{N}$. Fez-se 5 aplicações de $\mathrm{N}$, sendo a primeira aos 30 dias após a semeadura. A germinação ocorreu 15 dias após a semeadura, sendo então realizado o desbaste deixando-se apenas a plântula mais vigorosa por recipiente.

O delineamento experimental utilizado foi o de blocos ao acaso, em esquema fatorial 5 (doses de nitrogênio) $\times 2$ (tipos de substratos), com 4 repetições e cinco plantas por parcela, perfazendo um total de 200 plantas.

A duração do experimento foi de 120 dias, quando então as mudas apresentavam condições ideais para serem levadas ao campo, sendo então avaliados o comprimento da parte aérea e raiz $(\mathrm{cm})$, número de folhas e massa seca da raiz, parte aérea e total (g planta $\left.{ }^{-1}\right)$

A determinação do comprimento da parte aérea e da raiz foi realizada com uma régua graduada em centímetros, medindo-se a distância entre o colo e o ápice de cada muda.

As massas secas da raiz e da parte aérea foram obtidas após secagem em estufa de circulação de ar forçada a $60^{\circ} \mathrm{C}$, até atingirem peso constante, procedendo a pesagem em balança analítica.

Os resultados foram submetidos à análise de variância e as médias dos dados qualitativos comparadas pelo teste de Tukey a 1 e $5 \%$ de probabilidade, e para os dados quantitativos foi utilizada a análise de regressão (Gomes, 2000). 


\section{RESULTADOS E DISCUSSÃO}

Observando-se as análises químicas dos dois substratos A e B (Tabela 1), os valores correspondentes ao substrato $B$, superam os do substrato $\mathrm{A}$, com exceção do $\mathrm{pH}, \mathrm{V}$ e P-rem. Assim é possível inferir que o Plantmax ${ }^{\circledR}$ seja mais rico em nutrientes do que o Provaso $^{\circledR}$, resultado este também observado por Negreiros et al. (2004) e Ribeiro et al. (2005).

TABELA 1 - Resultados da análise química dos substratos utilizados no experimento com maracujazeiro amarelo. Lavras, MG, 2004.

\begin{tabular}{|c|c|c|c|c|c|c|c|c|c|c|c|c|c|}
\hline Subst. & $\mathrm{pH}$ & $\mathrm{P}$ & $\mathrm{K}$ & $\mathrm{Ca}$ & $\mathrm{Mg}$ & Al & $\mathrm{H}+\mathrm{Al}$ & SB & $\mathrm{t}$ & $\mathrm{T}$ & V & M.O & P-rem \\
\hline & $\mathrm{H}_{2} \mathrm{O}$ & \multicolumn{2}{|c|}{$\mathrm{mg} \mathrm{dm}^{-3}$} & \multicolumn{7}{|c|}{ - $\mathrm{cmol}_{\mathrm{c}} \mathrm{dm}^{-3}$} & $\%$ & $(\%)$ & $\mathrm{mg} \mathrm{dm}^{-3}$ \\
\hline A & 6,0 & 15,0 & 72,0 & 4,0 & 1,4 & 0,0 & 1,9 & 5,6 & 5,6 & 7,5 & 77,4 & 1,6 & 15,1 \\
\hline B & 5,7 & 49,8 & $\begin{array}{c}186 \\
0\end{array}$ & 5,1 & 1,8 & 0,0 & 2,3 & 7,4 & 7,4 & 9,6 & 77,1 & 1,9 & 12,2 \\
\hline
\end{tabular}

SB - soma de bases; t - CTC efetiva; T - CTC a pH 7,0; $\mathrm{V}$ - saturação de bases

Observa-se também, que o substrato $B$ apresenta valores mais expressivos em relação a quase todos os nutrientes, principalmente em relação ao $\mathrm{P}$ e $\mathrm{K}$ (Tabela 1 ), que são nutrientes de grande importância para a cultura do maracujazeiro. Notadamente o potássio, cuja falta ocasiona clorose seguida de necrose a partir das folhas mais velhas, secamento das gavinhas, redução na ramificação, redução no diâmetro dos ramos, queda acentuada de flores e alteração do teor de sólidos solúveis dos frutos (Junqueira et al., 1999). Além disso, o substrato $\mathrm{B}$ possui teores mais acentuados de $\mathrm{Fe}$ e $\mathrm{S}$ e um pequeno teor acima de $\mathrm{Mn}$ e $\mathrm{Cu}$ quando comparado ao substrato $A$. Entretanto o substrato $A$ possui teores mais elevados de $\mathrm{Zn}$ e um pequeno teor acima de $B$ quando comparado ao substrato B (Tabela 2).

TABELA 2 - Resultados da análise de nutrientes dos substratos utilizados no experimento com maracujazeiro amarelo. Lavras - MG, 2004.

\begin{tabular}{|c|c|c|c|c|c|c|}
\hline Substrato & $\mathrm{Zn}$ & $\mathrm{Fe}$ & $\mathrm{Mn}$ & $\mathrm{Cu}$ & B & S \\
\hline -- & ----- & -------- & - & ---- & 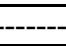 & \\
\hline A & 3,4 & 49,6 & 20,7 & 2,0 & 1,0 & 13,8 \\
\hline$B$ & 1,9 & 118,2 & 23,1 & 2,1 & 0,9 & 29,3 \\
\hline
\end{tabular}

De acordo com a análise de variância, houve efeito significativo para doses de nitrogênio para as variáveis comprimento da parte aérea e raiz (Tabela 3). Esses resultados mostram a alta influência que este elemento exerce, corroborado por Siqueira et al. (2002), interferindo no crescimento e desenvolvimento das mudas, em maior ou menor nível.

TABELA 3 - Resumo da análise de variância do comprimento da parte aérea (CPA), comprimento da raiz (CR), número de folhas (NF), massa seca da parte aérea (MSPA), raiz (MSR) e total MST), em função das doses de nitrogênio e dos substratos na produção de mudas de maracujazeiro Amarelo. La-

\begin{tabular}{lccccccc}
\hline FV & GL & CPA $(\mathrm{cm})$ & CR $(\mathrm{cm})$ & NF & MSPA $(\mathrm{g})$ & MSR $(\mathrm{g})$ & MST $(\mathrm{g})$ \\
\hline Nitrogênio (N) & 4 & $28,220^{* *}$ & $5,658^{*}$ & $7,592^{* *}$ & $0,577^{* *}$ & $0,036^{*}$ & $0,861^{* *}$ \\
Substrato (S) & 1 & $2,793^{\mathrm{ns}}$ & $0,021^{\mathrm{ns}}$ & $3,417^{*}$ & $0,523^{* *}$ & $0,129^{* *}$ & $1,170^{* *}$ \\
$\mathrm{~N} \times \mathrm{S}$ & 4 & $2,226^{\mathrm{ns}}$ & $1,728^{\mathrm{ns}}$ & $0,462^{\mathrm{ns}}$ & $0,203^{* *}$ & $0,041^{*}$ & $0,422^{* *}$ \\
Bloco & 3 & 4,219 & 3,657 & 0,303 & 0,029 & 0,022 & 0,080 \\
Resíduo & 27 & 2,452 & 1,006 & 1,058 & 0,039 & 0,011 & 0,085 \\
\hline CV(\%) & & 16,63 & 5,98 & 13,96 & 29,91 & 41,59 & 31,68 \\
\hline
\end{tabular}

${ }^{\star *}$ Significativo a $1 \%$ de probabilidade pelo teste $\mathrm{F} ;{ }^{*}$ Significativo a $5 \%$ de probabilidade pelo teste $\mathrm{F}$ e ${ }^{\mathrm{ns}}$ não significativo. 
CARPONI C. M., et al. Substratos e adubação nitrogenada...

Para o comprimento da parte aérea e de raiz, a regressão quadrática apresentou melhores ajustes, sendo atingindo $11,26 \mathrm{~cm}$ de comprimento da parte aérea quando aplicado uma dose de $1.888,85 \mathrm{mg} \mathrm{dm}^{-3}$ de $\mathrm{N}$ e $17,23 \mathrm{~cm}$ de comprimento da raiz quando aplicado uma dose de $264,26 \mathrm{mg}$ $\mathrm{dm}^{-3}$ de $\mathrm{N}$ (Figuras 1 e 2). A partir destas doses houve um efeito contrário, caracterizado como super dosagem de N. Lopes et al. (1999) ao estudarem o efeito do nitrogênio sobre mudas de maracujazeiro amarelo, verificaram um decréscimo do comprimento da parte aérea a partir de $17,3 \mathrm{~cm}$.

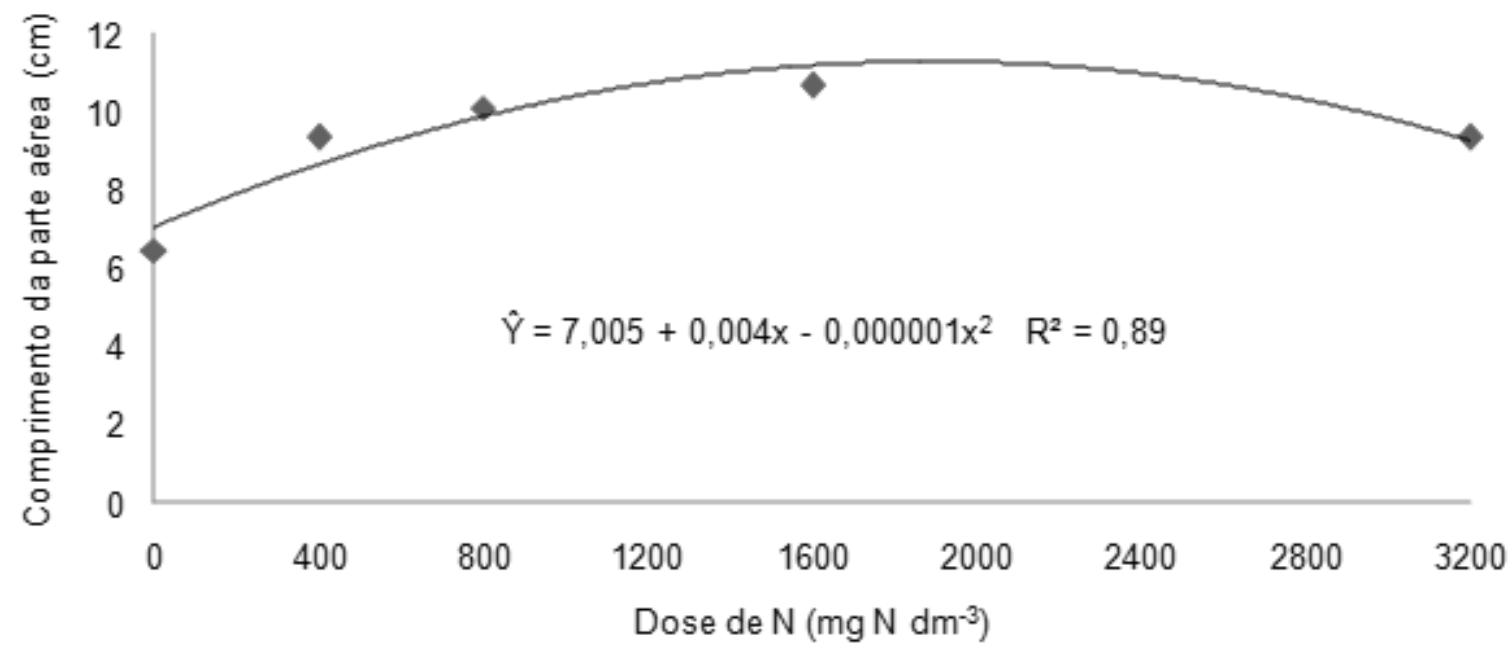

FIGURA 1 - Comprimento da parte aérea de mudas de maracujazeiro-amarelo em função da aplicação de nitrogênio. Lavras, MG, UFLA, 2005.

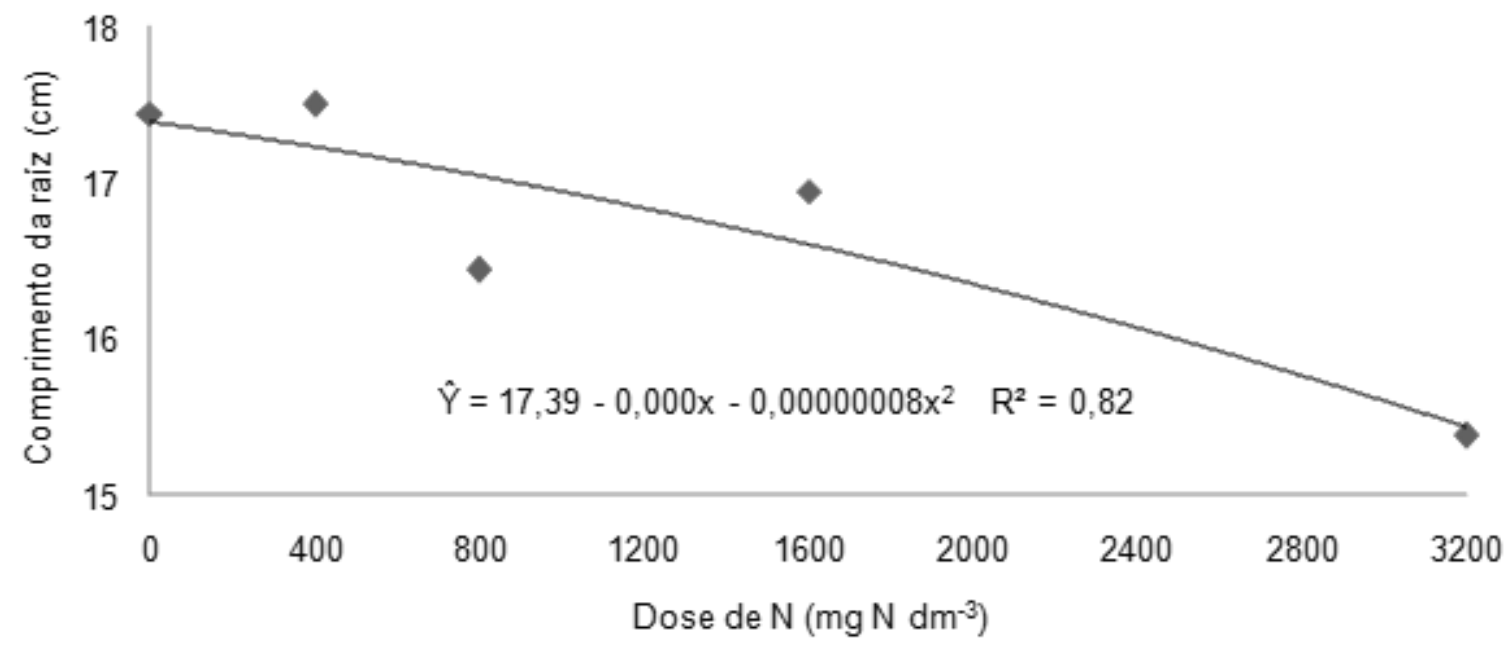

FIGURA 2 - Comprimento de raiz de mudas de maracujazeiro amarelo em função da aplicação de nitrogênio. Lavras, MG, UFLA, 2005.

A redução do comprimento da parte aérea pode ser sido influenciado por vários fatores. Como a uréia no solo transforma-se rapidamente em amônio (Mello, 1987; Decarlos Neto, 2002), acredita-se que possivelmente em concentrações crescentes as mudas possam ter absorvido maior quantidade de $\mathrm{N}$ na forma amoniacal. Portanto, o efeito negativo da uréia sobre a altura esteja em função da toxidez do amônio. Outro fator que pode ter influenciado é o efeito tóxico causado pelo íon amônio, o qual reduz a absorção de cátions, podendo ter causado inibi- ção do crescimento das plantas, principalmente o $\mathrm{Mg}$ que depois do $\mathrm{N}$ é o elemento que mais limita o crescimento em altura de plantas jovens de maracujazeiro (Fernandes et al., 1991).

Além disso, Souza et al. (2007) verificaram que alta dose de $\mathrm{N}$ ( $3.200 \mathrm{mg} \mathrm{N} \mathrm{dm}^{-3}$ no substrato) causou efeito depressivo para comprimento da parte aérea, comprimento da raiz, número de folhas, massa seca da parte aérea e da raiz. 
CARPONI C. M., et al. Substratos e adubação nitrogenada...

A dose de $1.696,84 \mathrm{mg} \mathrm{dm}^{-3}$ de $\mathrm{N}$ proporcionou maior de número de folhas $(8,57$ folhas $)$, sendo a equação quadrática a que melhor se ajustou (Figura 3). O substrato A proporcionou maior núme- ro de folhas $(7,25$ folhas) quando comparado ao substrato B $(6,62$ folhas) (Figura 4$)$

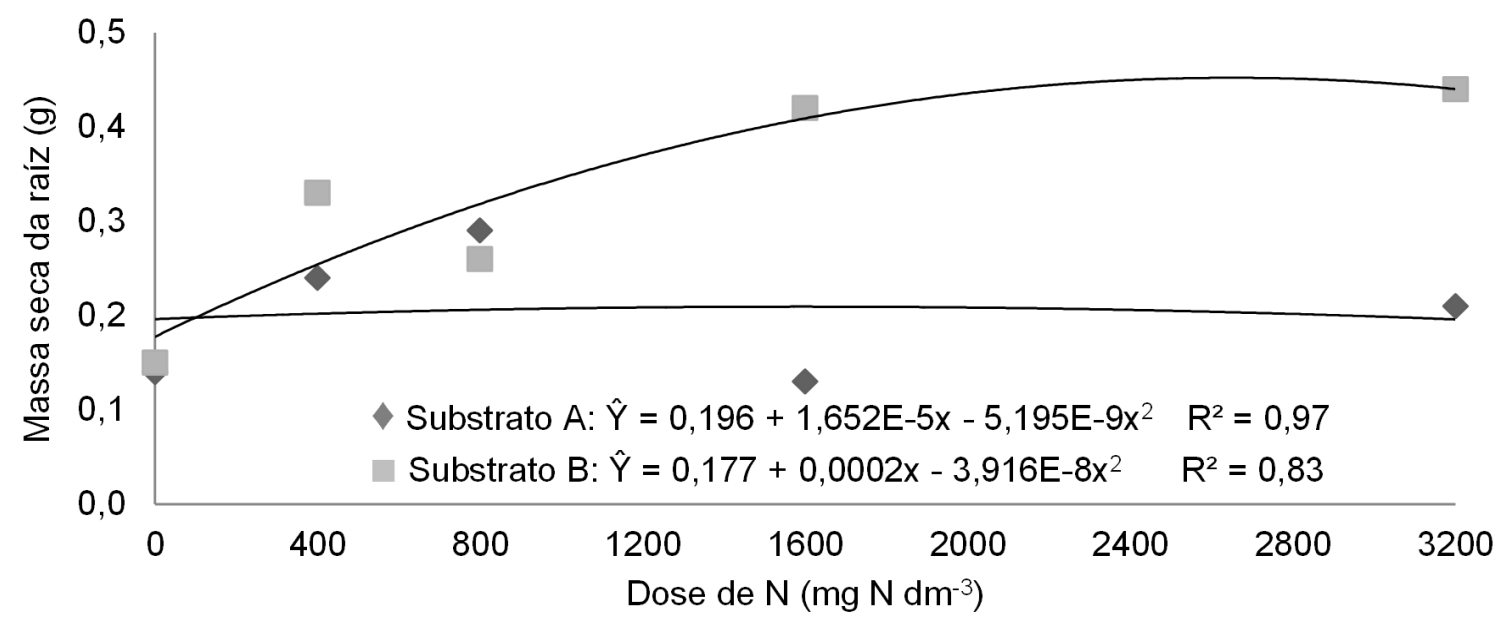

FIGURA 3 - Número de folhas de mudas de maracujazeiro amarelo em função da aplicação de nitrogênio. Lavras, MG, UFLA, 2005.

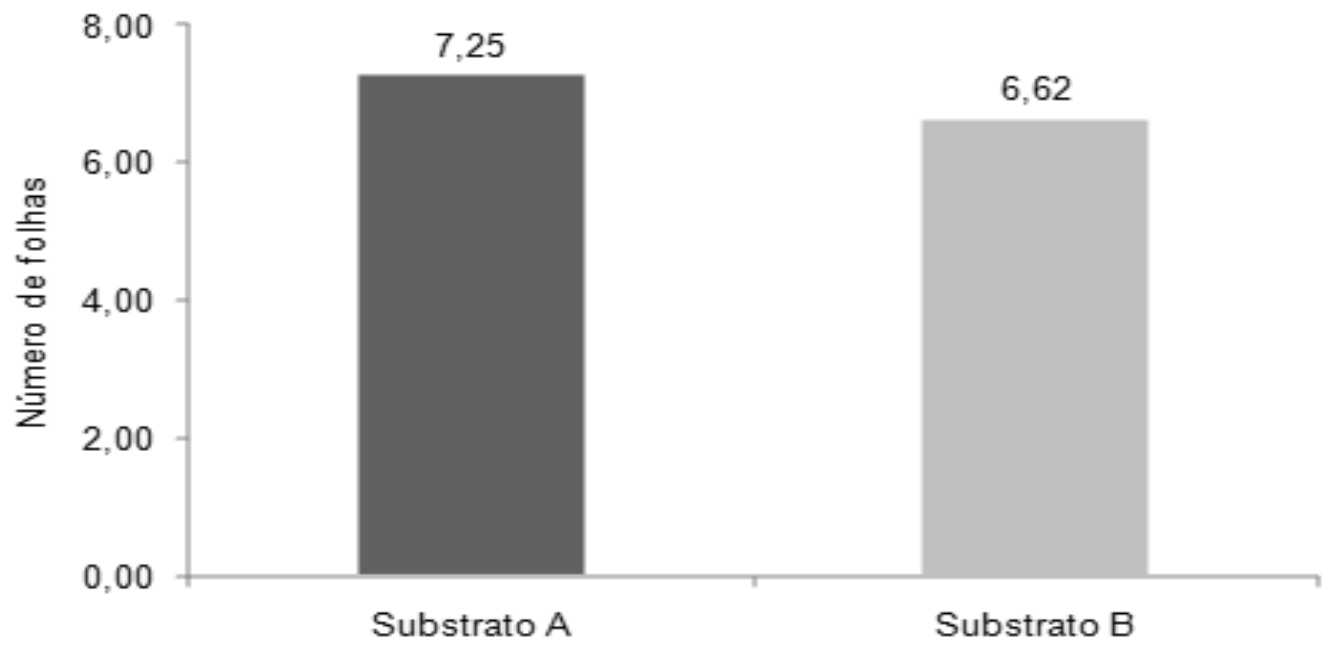

FIGURA 4 - Número de folhas de mudas de maracujazeiro amarelo em função dos substratos. Lavras, MG, UFLA, 2005.

Para massa seca da parte aérea, raiz e total o substrato A apresentou 0,$84 ; 0,21$ e $0,88 \mathrm{~g}$ quando aplicado $1.839,18 ; 1.589,87$ e $1,472,17 \mathrm{mg}$ $\mathrm{dm}^{-3}$ de $\mathrm{N}$ respectivamente (Figura 5,6 e 7 ). O substrato $B$ apresentou maiores resultados para as mesmas variáveis avaliadas, 1,$21 ; 0,43$ e $1,83 \mathrm{~g}$ quando aplicados $1.944,77 ; 2.553,69$ e $2.194,32 \mathrm{mg}$ $\mathrm{dm}^{-3}$ de $\mathrm{N}$ respectivamente.

Pode-se verificar, neste trabalho, que a utilização do nitrogênio demonstrou ser de grande importância na formação da muda do maracujazeiro amarelo. Quando se compara o valor da massa seca total da testemunha $(0,391 \mathrm{~g})$ com a massa seca total da muda na dose ótima de $\mathrm{N}(2.194,32$ $\mathrm{mg} \mathrm{N} \mathrm{dm}{ }^{-3}$ ) que foi de $1,83 \mathrm{~g}$, verifica-se um ganho de $368 \%$, confirmando a importância da utilização deste elemento para a formação de mudas desta frutífera.

Os resultados obtidos são corroborados por Silva et al. (2001), os quais verificaram melhores resultados na formação de mudas do maracujazeiro em substratos com valores mais elevados de nutrientes, o que é encontrado no substrato $B$. Segundo Decarlos Neto et al. (2002), a maioria dos substratos necessita de complementação com adubações de cobertura, principalmente com nitrogênio. 
CARPONI C. M., et al. Substratos e adubação nitrogenada...

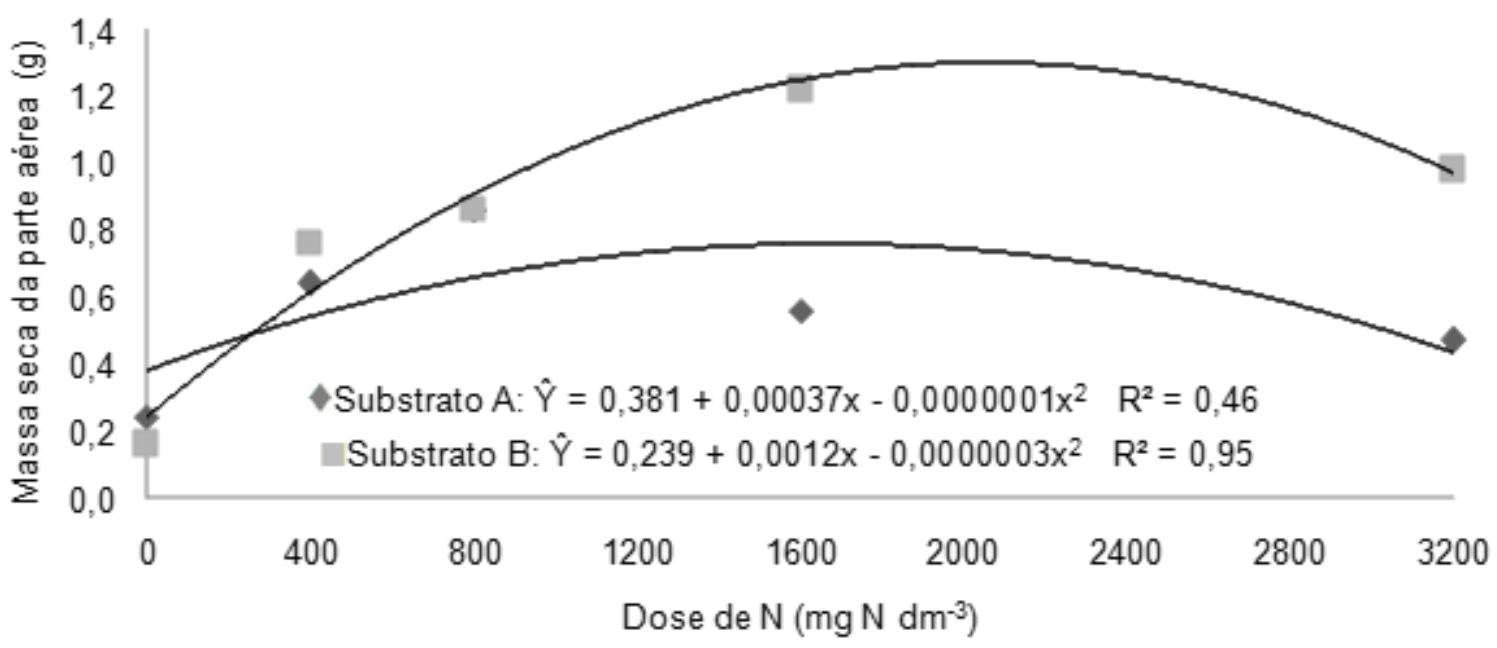

FIGURA 5 - Massa seca da parte aérea de mudas de maracujazeiro amarelo em função da aplicação de nitrogênio e dos substratos. Lavras, MG, UFLA, 2005.

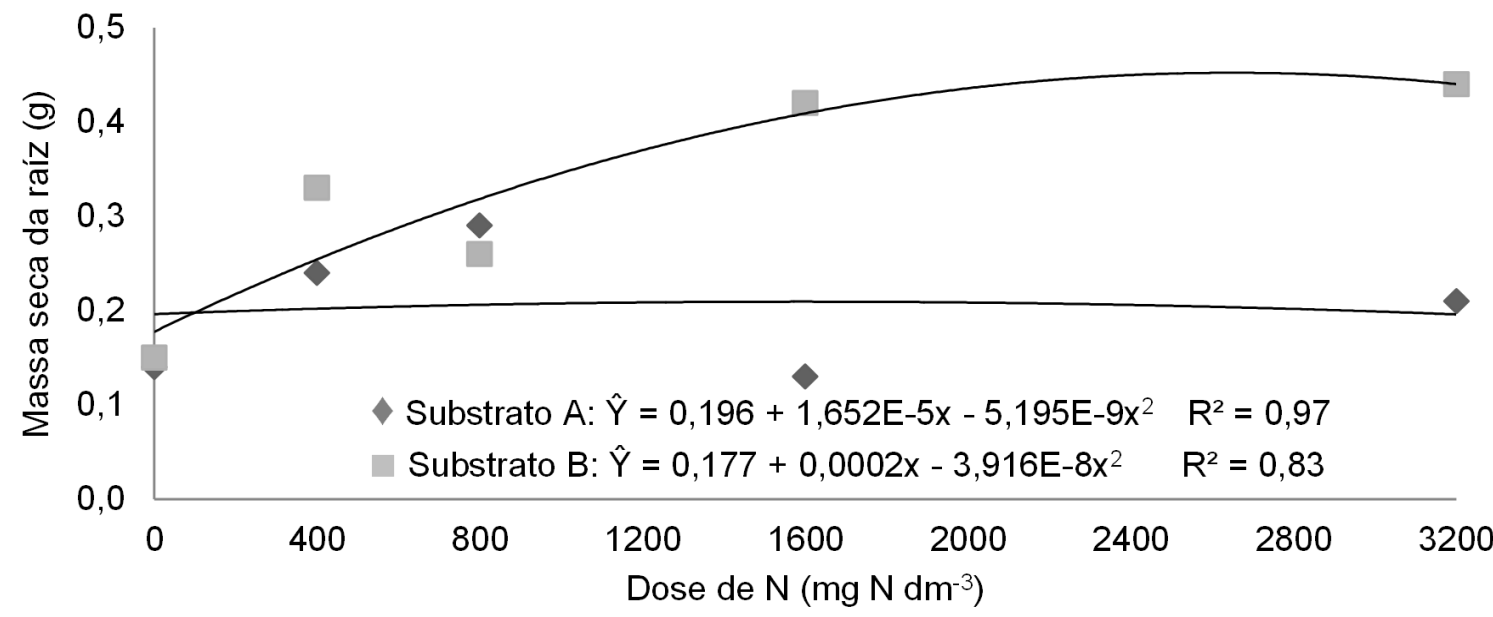

FIGURA 6 - Massa seca da raiz de mudas de maracujazeiro amarelo em função da aplicação de nitrogênio e dos substratos. Lavras, MG, UFLA, 2005.

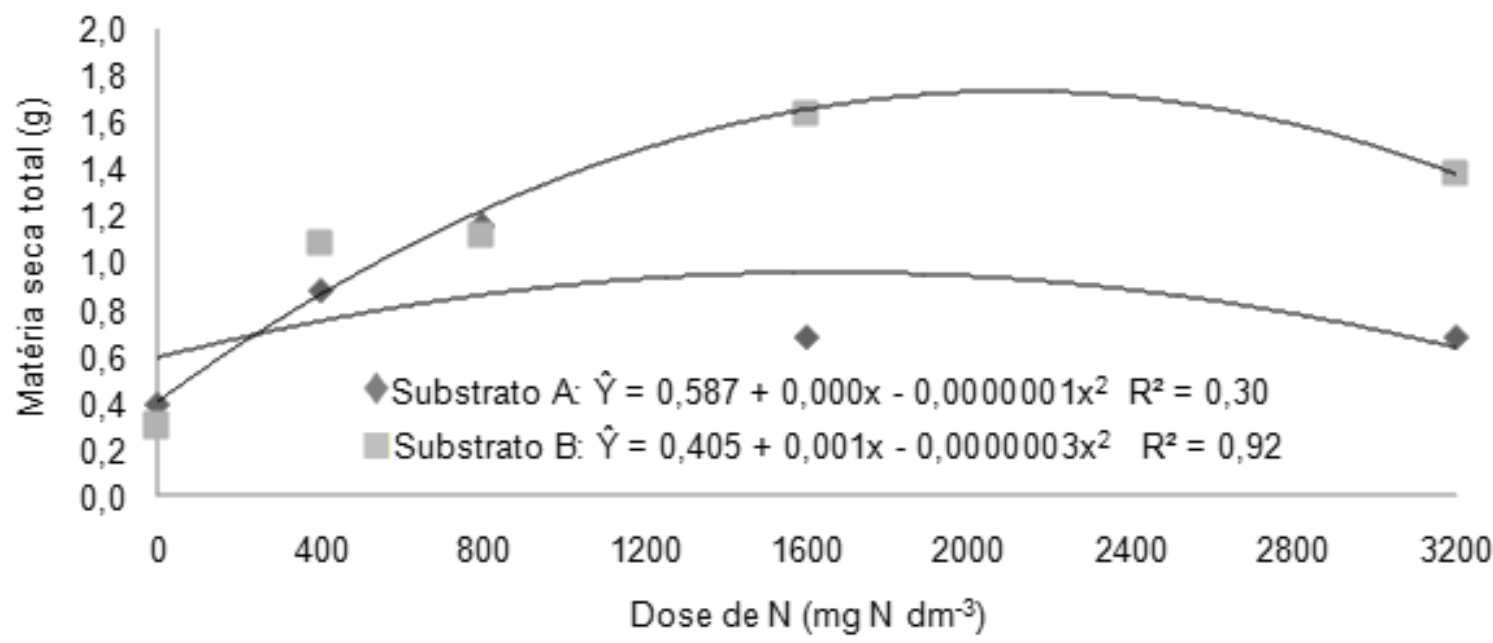

FIGURA 7 - Massa seca total de mudas de maracujazeiro amarelo em função da aplicação de nitrogênio e dos substratos. Lavras, MG, UFLA, 2005. 
CARPONI C. M., et al. Substratos e adubação nitrogenada...

\section{REFERÊNCIAS}

1. AGRIANUAL. Anuário da agricultura brasileira. São Paulo: FNP Consultoria e Comércio, 2008. $502 \mathrm{p}$

2. CARVALHO, J. A. et al. Desenvolvimento e produtividade do maracujazeiro-amarelo irrigado sob diferentes lâminas de irrigação em ambiente protegido e natural. Engenharia Agrícola, v. 30, n. 5, p. 862-874, 2010.

3. DECARLOS NETO, A. et al. Crescimento de porta-enxertos de citros em tubetes influenciados por doses de N. Revista Brasileira de Fruticultura, v. 24, n. 1, p. 199-203, 2002.

4. FACHINELLO, J. C.; HOFFMANN, A.; NACHTIGAL, J. C. Propagação de plantas frutíferas. Brasília: Embrapa, 2005. $221 \mathrm{p}$.

5. FANTI, S. C.; PEREZ, S. C. J. G. A. Influência do substrato e do envelhecimento acelerado na germinação de olho-de -dragão (Adenanthera pavonina L. - Fabaceae). Revista Brasileira de Sementes, v. 21, n. 2, p. 135-141, 1999.

6. FERNANDES, D. M. et al. Caracterização de sintomas de carência de macronutrientes em plantas de maracujá amarelo (Passiflora edulis Sims j. flavicarpa Deg.) cultivados em solução nutritiva. Revista Brasileira de Fruticultura, v. 13, n. 4, p. 233-240, 1991.

7. FREITAS, C. A. S. et al. Sistema radicial do maracujazeiro irrigado submetido a diferentes níveis de potássio. Scientia Agraria, v. 10, n. 3, p. 175-183, 2009.

8. GOMES, F. P. Curso de estatística experimental. 14 ed. Piracicaba: USP, 2000. 477 p.

9. JUNQUEIRA, N. T. V. et al. Cultura do maracujazeiro. In: SILVA, J. M. M. (Ed.). Incentivo à fruticultura no Distrito Federal: Manual de fruticultura. 2. ed. Brasília: OCDF, COOLABORA. p. 42-52, 1999.

10. LOPES, P. S. N. et al. Adubação nitrogenada e substratos no crescimento de mudas de maracujazeiro amarelo em tubetes. Revista Universidade de Alfenas, v. 5, p. 3-8, 1999.

11. MELETT, L. M. M.; QUAGGIO, J. A. Maracujá Passiflora spp. In: FAHL, J. I. et al. (Ed.) Instruções agrícolas para as principais culturas econômica. Campinas: Instituto Agronômico, p. 142-144, 1998 (Boletim Técnico 200).

12. MELLO, F. A. F. Uréia Fertilizante. Campinas: Fundação Cargill, 1987. 192 p.

13. NEGREIROS, J. R. S. et al. Diferentes substratos na formação de mudas de maracujazeiro-amarelo. Ceres, v. $51, n$. 294, p. 243-245, 2004.

14. RAMOS, J. D. et al. Produção de mudas de plantas frutíferas por sementes. Informe Agropecuário, v. 23, n. 216, p 64-72, 2002.

15. RIBEIRO et al. Produção de mudas de maracujá-amarelo com diferentes substratos e recipientes. Caatinga, v. 18, n. 3, p. 155-158, 2005.

16. RIZZI, L. C. et al. Cultura do maracujá azedo. Campinas: CATI, 1998, 54 p. (Boletim técnico 235).

17. SÃO JOSÉ, A. R. et al. Formação de mudas de maracujazeiro. In: SÃO JOSÉ, A. R. (ed.). Maracujá: produção e mercado. Vitória da Conquista, UESB, p. 41-48, 1994.

18. SIQUEIRA, D. L. et al. Produção de Mudas de Maracujazeiro Amarelo (Passiflora edulis f. flavicarpa DEG.) em Recipientes e Adubadas com Doses de Nitrogênio. In: CONGRESSO BRASILEIRO DE FRUTICULTURA, 17, Belém, 2002. Anais...SBF, 2002. CD ROM.

19. SILVA, R. P.; PEIXOTO, J. R.; JUNQUEIRA, N. T. V. Influência de diversos substratos no desenvolvimento de mudas de maracujazeiro azedo (Passiflora edulis Sims f. flavicarpa DEG). Revista Brasileira de Fruticultura, v. 23, n. 2, p. 377-381, 2001.

20. SOUZA, H. A. et al. Adubação nitrogenada e substratos na produção de mudas de maracujazeiro doce. Ciência e Agrotecnologia, v. 31, n. 3, p. 599-604, 2007.

21. SOARES, I.; LIMA, S. C.; CRISÓTOMO, S. A. Crescimento e composição mineral de mudas de gravioleira em resposta a doses de fósforo. Revista Ciência Agronômica, v. 38, n. 4, p. 343-349, 2007.

Recebido em 21/12/2009

Aceito em 05/08/2013 